\title{
Protective Effects of Phoenixin-14 Peptide in the Indomethacin-Induced Duodenal Ulcer: An Experimental Study
}

\author{
Yaser Zandeh-Rahimi ${ }^{1} \cdot$ Negar Panahi $^{1}$ (1) - Saeed Hesaraki ${ }^{2} \cdot$ Seyed Hamed Shirazi-Beheshtiha ${ }^{3}$
}

Accepted: 29 October 2021 / Published online: 3 January 2022

(c) The Author(s), under exclusive licence to Springer Nature B.V. 2022

\begin{abstract}
Phoenixin-14 (PNX 140$)$ is a newly identified neuropeptide with potential anti-inflammatory effects in the gastrointestinal tract. In this study, we evaluated the protective effect of PNX-14 against the formation of experimental indomethacin (IND)induced duodenal ulcer. Thirty-two'male Sprague-Dawley rats were randomly assigned to the four following study groups: (1) negative control (2) IND (7.5 mg/kg subcutaneous IND), (3) famotidine (FA) (7.5 mg/kg subcutaneous IND followed by $40 \mathrm{mg} / \mathrm{kg}$ intraperitoneal'FA), and (4) PNX-14 (7.5 mg/kg subcutaneous IND followed by $50 \mu / \mathrm{kg}$ intraperitoneal'PNX-14). Outcome measures included macroscopic evaluation of duodenal lesion, serum levels of IL-1ß, TNF- $\alpha$, IL-6, and IL-12, and tissue biochemical parameters of oxidative stress, including malondialdehyde (MDA)titmyeloperoxidase (MPO) activity, superoxide dismutase (SOD) lactivity, and catalase activity. Results The macroscopic grade of duodenal lesions were significantly smaller in the PNX-14 group than in the IND group $(\mathrm{p}<0.001)$. Serum inflammatory cytokines were significantly increased in the IND group. PNX-14 treatment significantly decreased the serum levels of inflammatory cytokines $(\mathrm{p}<0.0001)$. Oxidative contents (MDA and MPO activity) were significantly smaller in the PNX-14 group compared with the IND group ( $\mathrm{p}<0.0001)$, while anti-oxidative contents (SOD and catalase activity) were significantly more $(\mathrm{p}<0.0001)$. PNX-14 was superior to FA in several anti-inflammatory properties, such as inhibiting the release of inflammatory cytokines and increasing the catalase activity. PNX-14 showed significant protective effects against the formation of IND-induced duodenal ulcers. These results suggest a promising therapeutic implication for PNX-14 in the treatment of gastrointestinal inflammatory disorders.
\end{abstract}

Keywords Phoenixin-14 $\cdot$ Neuropeptide $\cdot$ Antioxidant activity $\cdot$ Inflammatory cytokines $\cdot$ Duodenal ulcer

\section{Introduction}

Several homeostatic functions are regulated by the neuro/ humoral interplay between the central nervous system and the gastrointestinal tract (Carabotti et al. 2015; De Vadder and Mithieux 2015; ‘Abdullah et al. 2020). Several disorders have also been linked to this axis's dysfunction, including gastrointestinal diseases such as irritable bowel syndrome and psychiatric disorders such as depression and autism

Negar Panahi

n.panahi@srbiau.ac.ir

1 Department of Veterinary Basic Sciences, Science and Research Branch, Islamic Azad University, Tehran, Iran

2 Department of Veterinary Pathobiology, Science and Research Branch, Islamic Azad University, Tehran, Iran

3 Department of Veterinary Pathobiology, Karaj Branch, Islamic Azad University, Karaj, Iran spectrum disorder (Buhmann et al. 2014; Mayer et al. 2014; Luna and Foster 2015;'Dinan and Cryan 2017; Sinagra et al. 2020). Restoration of this function is shown to contain therapeutic implications (Bonaz et al. 2018; Sinagra et al. 2020).

Phoenixin|(PNX|) is a newly discovered peptide of the gut-brain axis with two active isoforms: PNX-14 and PNX20. It is shared between several species, including humans and rodents, in a highly conserved structure. Initially, PNX14 was identified as a reproductive peptide. Later, it was acknowledged as a pleiotropic gut-brain peptide with several additional physiological roles such as inhibiting visceral pain, inducing anxiety, improving memory retention, and eliciting pruritus (Yuan et al. 2017;; Schalla and Stengel 2018). Recently, the protective effects of PNX-14 against lipopolysaccharide-induced inflammation have also been demonstrated (Wang et al. 2020).

Inflammatory bowel diseases (IBD) are a group of chronic intestinal inflammatory disorders with a relapsing 
and remitting clinical course and two main subgroups: Crohn's disease (CD) and ulcerative colitis (UC). Despite effective therapeutic modalities, a subset of patients either do not respond to therapy or lose response over time. Therefore, the identification of new therapeutic options is of considerable value (Hazel and O'Connor 2020).

Although IBD etiology is not well understood, it has been attributed to the host-microbial interactions in individuals with genetic susceptibility, causing an aberrant immune response to the gut microbiota (Fakhoury et al. 2014). Furthermore, it is known that the gut microbiota, the enteric nervous system, and gut hormones are particularly interrelated (Schalla and Stengel 2018). Considering PNX-14 as a neuropeptide in the gut-brain axis (Wei et al. 2020), its potential role in gut microbial balance and immunomodulation (Hansen and Sartor 2015; Schalla and Stengel 2018), and its anti-inflammatory properties (Wang et al. 2020), we hypothesized that it could be involved in the pathogenesis of gastrointestinal inflammatory disorders such as IBD. If so, PNX-14 supplementation might have therapeutic implications in the management of these disorders. This study aimed to find if PNX-14 protects against experimental indomethacin (IND)-induced duodenal ulcer in the experimental model.

\section{Materials and Methods}

\section{Animals and Study Design}

This study was approved by the National Committee on Ethics in Biomedical Research /(ethics.research.ac.ir) of the Islamic Azad University, Science and Research Branch and approved with the ethics ID IR.IAU.SRB.REC.1396.189." Moreover, according to Helsinki's ddeclaration, it iwas conducted with appropriate caution to respect the welfare of animals used in this research.?

In experimental research, a total of 324-month-old adult male Sprague-Dawley rats with an average weight of $220 \mathrm{~g}$ (range 200-250) were obtained from the animal house of our university. The rats were given a standard diet and kept under the temperature-controlled condition $\left(24 \pm 1^{\circ} \mathrm{C}\right)$ and $12 / 12$ hours' light/dark cycle. Rats were allocated into four study groups of eight rats using a simple randomization technique. The first group (negative control group) received the solvent liquid of IND (sodium bicarbonate, $0.1 \mathrm{ml} / 100 \mathrm{~g}$ ) subcutaneously for two consecutive days, with an interval of $24 \mathrm{~h}$. The second group (IND group) received subcutaneous IND $(7.5 \mathrm{mg} / \mathrm{kg})$ for two consecutive days, with an interval of $24 \mathrm{~h}$. The third group (positive control for PNX-14 effect) received subcutaneous IND $(7.5 \mathrm{mg} / \mathrm{kg})$ followed by intraperitoneallffamotidine ( $\mathrm{FA}, 40 \mathrm{mg} / \mathrm{kg}$ ), $15 \mathrm{~min}$ after the IND injection for three consecutive days, with an interval of $24 \mathrm{~h}$.
The fourth group (PNX-14 group) received subcutaneous IND $(7.5 \mathrm{mg} / \mathrm{kg})$ followed by intraperitoneal['PNX-14 (50 $\mu /$ $\mathrm{kg}$ ), $15 \mathrm{~min}$ after the IND injection for three consecutive days with an interval of $24 \mathrm{~h}$.

The rats were decapitated on the 4th day, and after collection of trunk blood and centrifugation at $3000 \mathrm{rpm}$ for $15 \mathrm{~min}$, the serum samples were extracted and kept at $-80{ }^{\circ} \mathrm{C}$ for further examinations. Subsequently, through a midline incision, the rats' intestine was extracted and weighted. The duodenal lesions were graded macroscopically. Then the intestinal tissues were stored at $-80^{\circ} \mathrm{C}$ for the analysis of biochemical parameters.

\section{Macroscopic Appearance of Intestinal Tissues}

Macroscopic grading of the duodenal ulcer was performed according to the scale introduced by Haber (1999). Accordingly, the lesions were graded on a $0-5$ scale as follows: no serous and mucosal change (grade 0 ), hyperemia and petechial hemorrhages (grade 1), single mucosal erosion plus ulceration (grade 2), single mucosal erosion plus ulceration, and hyperemia (grade 3 ), multiple mucosal erosion and ulceration $(<2 \mathrm{~cm})$ plus serosal erosion (grade 4$)$, multiple mucosal erosion and ulceration $(>2 \mathrm{~cm})$ plus serosal erosion (grade 5).

\section{Serum Inflammatory Cytokines}

According to the manufacturer protocol, serum samples were tested for the level of inflammatory cytokines, including IL-1ß, TNF- $\alpha$, IL-6, and IL-12, using an enzyme-linked immunosorbent assay.

\section{Biochemical Parameters}

\section{Malondialdehyde (MDA)}

The thiobarbituric acid reactive substances (TBARS) assay was used for MDA evaluation (De Leon and Borges 2020). After homogenizing the intestinal tissues in trichloroacetic acid $(15 \%)$ and extraction of supernatants, it was briefly exposed to thiobarbituric acid (TBA) and underwent $15 \mathrm{~min}$ centrifugation at $15,000 \mathrm{rpm}$ and $100{ }^{\circ} \mathrm{C}$, leading to the formation of MDA-TBA2 adducts called TBARS. The final redpink color was measured spectrophotometrically at $532 \mathrm{~nm}$.

\section{Myeloperoxidase (MPO) Activity}

After homogenization of intestinal tissues with $0.5 \%$ hexadecyltrimethylammonium bromide (HETAB) and centrifugation for $10 \mathrm{~min}$ at $12,000 \mathrm{rpm}$ and $4{ }^{\circ} \mathrm{C}$, supernatants were extracted and processed with $50 \mathrm{mM}$ potassium phosphate buffer, o-Dianisidine $(20 \mathrm{mg} / \mathrm{ml})$, and $\mathrm{H}_{2} \mathrm{O}_{2}(20 \mathrm{mM})$. After 
three min incubation at room temperature, the absorption was measured at $450 \mathrm{~nm}$ to estimate MPO activity (Krawisz et al. 1984).

\section{Superoxide Dismutase (SOD) Activity}

SOD activity was assessed using the riboflavin method (Bertrand and Eze 2014). Briefly, the tissues underwent centrifugation for $10 \mathrm{~min}$ at $4000 \mathrm{rpm}$. Then, the supernatants were exposed to $0.028 \mathrm{mM}$ riboflavin standard. Subsequently, the fluorescent light source $(20 \mathrm{w})$ generated superoxide anion radicals from light-excited riboflavin. Finally, the absorption was measured at $460 \mathrm{~nm}$ to estimate the SOD activity.

\section{Catalase Activity}

The tissues were centrifuged for $10 \mathrm{~min}$ at $4000 \mathrm{rpm}$. Then the supernatants were incubated with sodium-potassium phosphate buffer $(50 \mathrm{mM})$ and $\mathrm{H}_{2} \mathrm{O}_{2}(30 \mathrm{mM})$. Catalytic activity was measured following the decomposition of $\mathrm{H}_{2} \mathrm{O}_{2}$ and the release of $\mathrm{O}_{2}$. the absorption was measured at 240 nm (Shangari and O’Brien 2006).

\section{Statistical Analysis}

Statistical analysis was performed using GraphPad Prism version 9.00 for Windows (GraphPad Software, San Diego, California USA). Shapiro-Wilk test was used to test the normality of distribution. One-way analysis of variance (ANOVA) test or its nonparametric counterpart (Kruskal-Wallis H test) was used to compare mean values between more than two groups, followed by Dunnett's multiple comparisons test. Kruskal-Wallis test was also used for comparison of ordinal variables (macroscopic grade of ulcer). A p-value $<0.05$ was considered significant.

\section{Results}

\section{Macroscopic Evaluation of Intestinal Tissues}

Induction of duodenal ulcer by IND led to the appearance of the duodenal lesion in the IND, FA, and PNX-14 group. However, the grade of lesions was significantly lower in the FA and PNX-14 groups ( $\mathrm{p}<0.001$ for both). No ulcerative lesion was seen in the duodenum of the normal control group. The ulcer's grade was not significantly different between the FA and PNX-14 groups $(\mathrm{p}=0.39)$ (Table 1; Fig. 1).

\section{Serum Inflammatory Cytokines}

\section{IL-1ß}

The mean serum IL- $\beta$ level was significantly increased in the IND group compared to the negative control group (mean difference: $22.8 \mathrm{pg} / \mathrm{ml}, \mathrm{p}<0.0001$ ). FA and PNX-14 treatment significantly decreased the serum levels of IL-1ß as compared to the IND group (mean difference: $7.84 \mathrm{pg} /$ $\mathrm{ml}, \mathrm{p}=0.014$ and mean difference: $12.8 \mathrm{pg} / \mathrm{ml}, \mathrm{p}<0.0001$, respectively). Reduction of serum IL-1B was more significant in the PNX-14 group than the FA group (mean difference: $4.93 \mathrm{pg} / \mathrm{ml}, \mathrm{p}=0.018$ ) (Fig. 2a).

\section{TNF-a}

The mean serum TNF- $\alpha$ level was significantly increased in the IND group compared to the normal control group (mean difference: $28.1 \mathrm{pg} / \mathrm{ml}, \mathrm{p}<0.0001$ ). FA and PNX-14 treatment significantly decreased the serum levels of TNF- $\alpha$

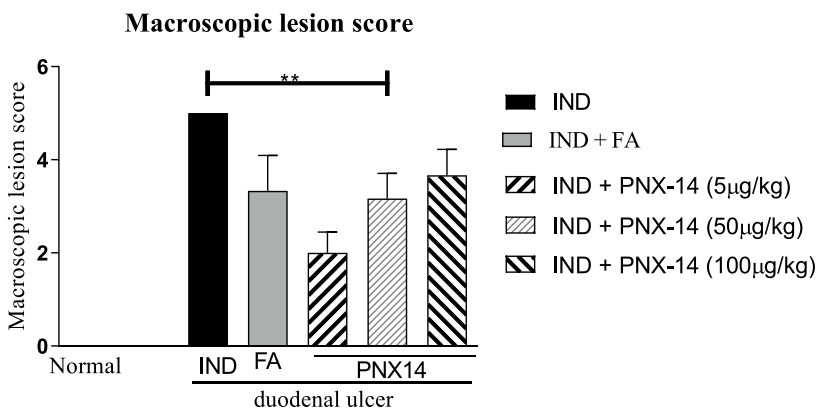

Fig. 1 Macroscopic evaluation of intestinal tissues showing a marked increase in the indomethacin (IND) group compared to the Normal group and a significant decrease in the Phoenixin (PNX-14) With different concentrations and Famotidine (FA) treated group compared to the IND group. Data are presented as mean \pm standard deviation. Asterisks indicate the level of significant difference: $* \mathrm{p}<0.05$, $* * \mathrm{p}<0.001$, and $* * *<0.001$
Table 1 Grade of duodenal ulcer in different study groups

\begin{tabular}{lllllll}
\hline Group & Grade 0 & Grade 1 & Grade 2 & Grade 3 & Grade 4 & Grade 5 \\
\hline Negative control & 8 & 0 & 0 & 0 & 0 & 0 \\
IND group & 0 & 0 & 2 & 2 & 3 & 1 \\
IND + FA group & 0 & 2 & 4 & 2 & 0 & 0 \\
IND + PNX-14 group & 1 & 2 & 4 & 1 & 0 & 0 \\
\hline
\end{tabular}

$I N D$ indomethacin; FA famotidine; $P N X-14$ Phoenixin-14 

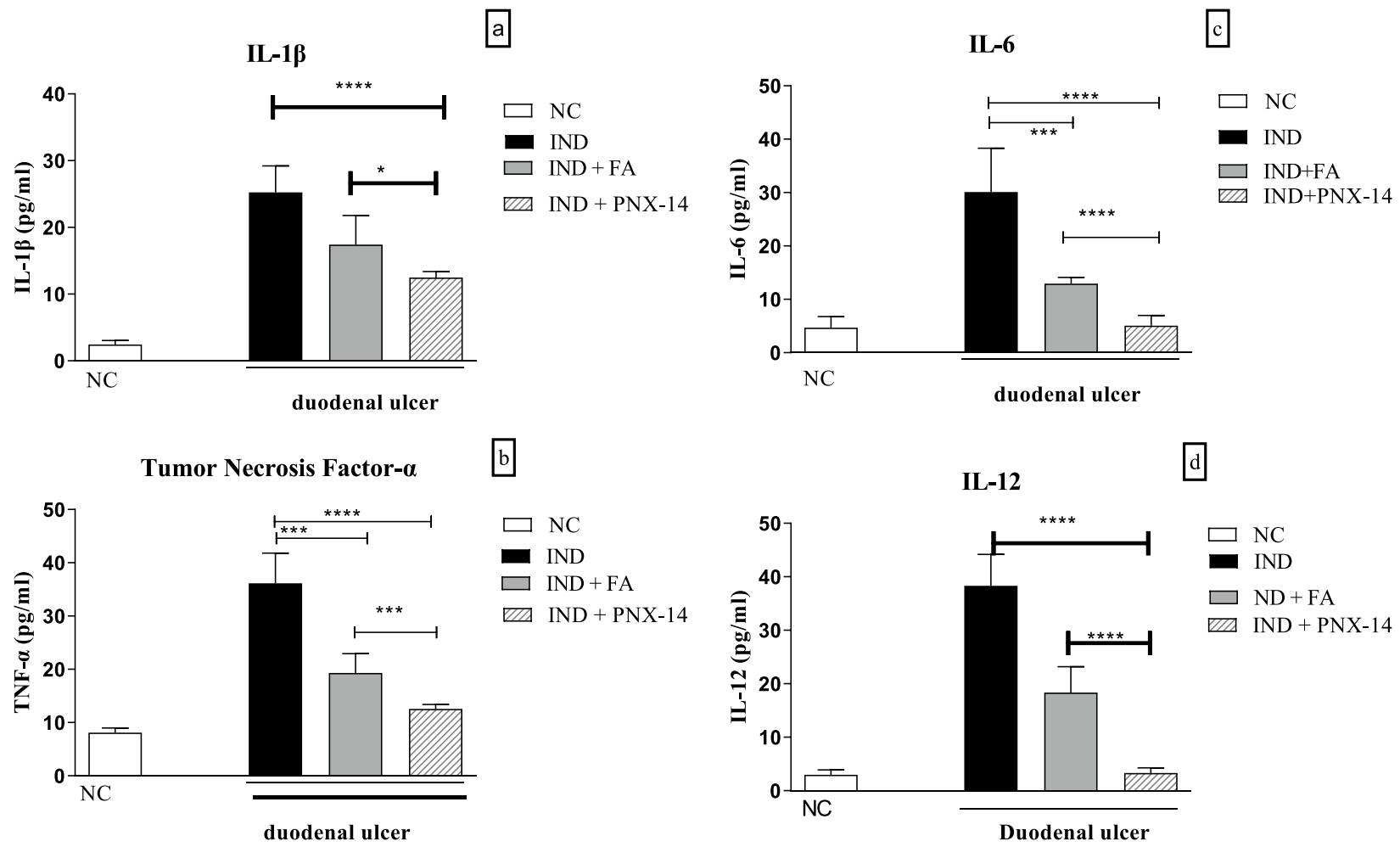

Fig. 2 Evaluation of serum levels of IL-1ß a, TNF- $\alpha$ b, IL-6 c, and IL-12 d showing a marked increase in the indomethacin (IND) group compared to the negative control (NC) group and a significant decrease in the Phoenixin (PNX-14) and Famotidine (FA) treated

as compared to the IND group (mean difference: $16.8 \mathrm{pg}$ / $\mathrm{ml}, \mathrm{p}=0.0005$ and mean difference: $23.6 \mathrm{pg} / \mathrm{ml}, \mathrm{p}<0.0001$, respectively). Reduction of serum TNF- $\alpha$ was more significant in the PNX-14 group than the FA group (mean difference: $6.78 \mathrm{pg} / \mathrm{ml}, \mathrm{p}=0.005$ ) (Fig. 2b).

\section{IL-6}

The mean serum IL-6 level was significantly increased in the IND group compared to the normal control group (mean difference: $25.4 \mathrm{pg} / \mathrm{ml}, \mathrm{p}<0.0001)$. FA and PNX-14 treatment significantly decreased the serum levels of IL-6 as compared to the IND group (mean difference: $17.7 \mathrm{pg} / \mathrm{ml}, \mathrm{p}=0.0006$ and mean difference: $25 \mathrm{pg} / \mathrm{ml}, \mathrm{p}<0.0001$, respectively). Reduction of serum IL-6 was more significant in the PNX14 group than the FA group (mean difference: $12.9 \mathrm{pg} / \mathrm{ml}$, $\mathrm{p}=0.0008)($ Fig. 2c).

\section{IL-12}

The mean serum IL-12 level was significantly increased in the IND group compared to the normal control group group compared to the IND group. Data are presented as mean \pm standard deviation. Asterisks indicate the level of significant difference: $* \mathrm{p}<0.05, * * \mathrm{p}<0.001$, and $* * *<0.001$

(mean difference: $35.4 \mathrm{pg} / \mathrm{ml}, \mathrm{p}<0.0001$ ). FA and PNX-14 treatment significantly decreased the serum levels of IL-12 as compared to the IND group (mean difference: $20 \mathrm{pg} /$ $\mathrm{ml}, \mathrm{p}<0.0004$, and mean difference: $35 \mathrm{pg} / \mathrm{ml}, \mathrm{p}<0.0001$, respectively). The reduction of serum IL- 12 was more significant in the PNX-14 group than in the FA group (mean difference: $15 \mathrm{pg} / \mathrm{ml}, \mathrm{p}=0.0002$ ) (Fig. 2d).

\section{Antioxidant Activity}

\section{MDA}

The mean duodenal MDA was significantly increased in the IND group compared to the normal control group (mean difference: $40.1 \mathrm{nmol} / \mathrm{g}$ tissue, $\mathrm{p}<0.0001$ ). FA and PNX-14 treatment significantly decreased the duodenal MDA activity compared to the IND group (mean difference: $38.4 \mathrm{nmol} / \mathrm{g}$ tissue, $\mathrm{p}<0.0001$ and mean difference: $35.6 \mathrm{nmol} / \mathrm{g}$ tissue, $\mathrm{p}<0.0001$, respectively). The mean reduction of MDA activity was more significant in the FA group than the PNX-14 group (mean difference: $2.8 \mathrm{U} / \mathrm{g}$ tissue, $p=0.024$ ) (Fig. 3a). 
Fig. 3 a-d Evaluation of duodenal malondialdehyde (MDA) activity (a),, myeloperoxidase (MPO) activity (b), superoxide dismutase (SOD) activity (c), and catalase activity (d) in the study groups. Asterisks indicate the level of significant difference: NC; non-significant, $* \mathrm{p}<0.05, * * * * \mathrm{p}<0.0001$,
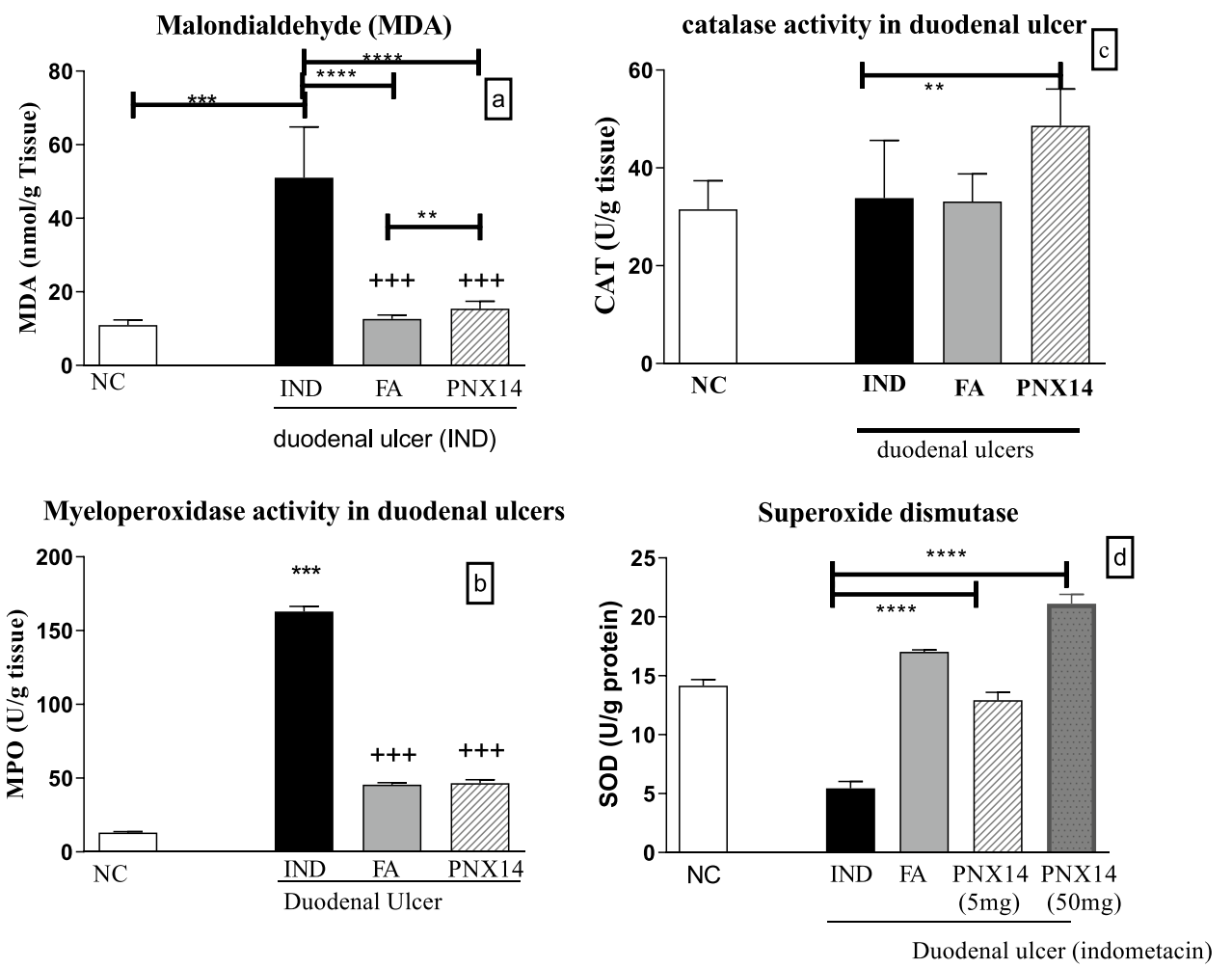

\section{MPO Activity}

The mean duodenal MPO activity significantly increased in the IND group compared to the normal control group (mean difference: $\lceil 149.8\lceil\mathrm{U} / \mathrm{g}$ tissue, $\mathrm{p}<0.0001)$. FA and PNX-14 treatment significantly decreased the duodenal MPO activity compared to the IND group (mean difference: $117.3 \mathrm{U} / \mathrm{g}$ tissue, $\mathrm{p}<0.0001$ and mean difference: $116.3 \mathrm{U} / \mathrm{g}$ tissue, $\mathrm{p}<0.0001$, respectively). The reduction of MPO activity was not significantly different between the FA and PNX-14 groups (mean difference: $1 \mathrm{U} / \mathrm{g}$ tissue, $\mathrm{p}=0.98)($ Fig. 3b).

\section{SOD Activity}

The mean duodenal SOD activity significantly decreased in the IND group compared to the normal control group (mean difference: $[8.7$ U/g protein, $\mathrm{p}<0.0001$ ). FA and PNX-14 treatment significantly increased the duodenal SOD activity compared to the IND group (mean difference: $13.6 \mathrm{U} / \mathrm{g}$ protein, $\mathrm{p}<0.0001$ and mean difference: $7.2 \mathrm{U} / \mathrm{g}$ protein, $\mathrm{p}<0.0001$, respectively). The mean elevation of SOD activity was significantly greater in the FA group than the PNX-14 group (mean difference: $6.4 \mathrm{U} / \mathrm{g}$ protein, $\mathrm{p}=0.03$ ) (Fig. 3c).

\section{Catalase Activity}

The mean duodenal catalase activity was not significantly different between the IND and normal control groups (mean difference: $2.3 \mathrm{U} / \mathrm{g}$ tissue, $\mathrm{p}=0.07)$. FA treatment did not significantly increase the duodenal catalase activity compared to the IND group (mean difference: $0.7 \mathrm{U} / \mathrm{g}$ tissue, $\mathrm{p}=0.47$ ), while PNX-14 treatment did (mean difference: $14.8 \mathrm{U} / \mathrm{g}$ tissue, $\mathrm{p}<0.0001$ ) (Fig. $3 \mathrm{~d}$ ).

\section{Discussion}

In this study, we investigated the protective effect of PNX14 against IND-induced duodenal ulcers in the laboratory model. According to our macroscopic observation, the severity of duodenal ulcers was significantly reduced when PNX-14 was also administered. The level of proinflammatory cytokines, including IL- $1 \beta$, TNF- $\alpha$, IL-6, and IL-12, was significantly lower in the serum samples of the rats who received PNX-14 than those who received IND alone. Besides, oxidative content (MDA and MPO activity) was significantly lower in the PNX-14 group, while anti-oxidative content (SOD and catalase activity) was significantly more. Compared to the FA group, the effects of PNX-14 on 
inhibiting the release of inflammatory cytokines and increasing the catalase activity were more significant.

To date, several potential roles have been suggested for PNX-14. The central nervous system has been attributed to improved memory recognition and mitigating memory impairment (Schalla and Stengel 2018). In addition, the reproductive system has been shown to potentiate LH secretion, control the estrus cycle, stimulate oocyte maturation, and increase the number of ovulated oocytes (Billert et al. 2020). Besides the effects of PNX-14 on the central nervous and reproductive system, its anxiolytic, anti-inflammatory, and cell-protective effects have also been demonstrated in several investigations (Billert et al. 2020).

The protective effect of PNX-14 against intestinal inflammation has not been revealed in any earlier investigations. However, experimental data support the presence of a neuronal connection between the gastrointestinal and central nervous system and the mediating role of neuropeptides in this interplay (Emge et al. 2016; Houser and Tansey 2017; Sinagra et al. 2020). In this respect, several studies have shown that psychological disorders are more prevalent in IBD patients (Graff et al. 2009; Walker et al. 2008). Besides, stress is attributed to aggravated IBD symptoms (Maaser et al. 2017). This bi-directional communication in the gutbrain axis is partly manipulated via neuropeptides (Wei et al. 2020).

Alteration of gut microbiota has been associated with several disorders such as IBD, in which changes of gut-associated neuropeptides have also been detected (Sanz and El Aidy 2019). Interestingly, neuropeptides are acknowledged as mediators in orchestrating the microbiota-gut-brain axis (Holzer and Farzi 2014; Hansen and Sartor 2015; Schalla and Stengel 2018) and immunomodulation (Chen et al. 2020; Nimer et al. 2020).

Nesfatin-1, a recently identified neuropeptide and an emerging player of the gut-brain axis, has been shown to contain protective effects against colitis induction in the experimental model, besides its anorexigenic, neuroprotective, and anti-apoptotic effects (Ozturk et al. 2015). Pałasz et al. revealed that PNX-14 is highly co-expressed with nesfatin-1 in the rat hypothalamus and suggested a potential functional relationship between these two neuropeptides (Pałasz et al. 2015). The present study reveals that PNX-14, similar to nesfatine-1, has protective effects against intestinal inflammation, suggesting a functional association between these peptides.

Recently, the anti-inflammatory effect of PNX-14 in astrocytes was shown in the study of Wang et al. In this respect, pretreatment of isolated mice astrocytes with PNX-14 suppressed the production of inflammatory cytokines, including IL-1 $\beta$ and IL-18. Moreover, the production of reactive oxygen species was suppressed. Accordingly, they suggested a potential role for PNX-14 in treating neuroinflammation (Wang et al.
2020). In the present study, PNX-14 supplementation reduced the severity of IND-induced duodenal ulcers, decreased serum levels of inflammatory cytokines, and suppressed the production of oxidative content. These observations suggest a protective role for PNX-14 against intestinal inflammation, which could have therapeutic utility in managing gastrointestinal inflammatory disorders such as IBD.

According to the present study, PNX-14 was superior to FA in modulating several duodenal inflammation indices, including proinflammatory cytokines and catalase activity. These observations further support the efficacy of PNX-14 as a promising agent in the management of gastrointestinal inflammatory conditions.

The main limitation of the present study was the lack of further confirmation of the microscopic changes of duodenal tissue through histopathologic examination. This limitation was caused by the COVID-19 pandemic, which forced the due research lab to shut down. Therefore, future complementary studies are required to shed more light on the anti-inflammatory effect of PNX in the gastrointestinal system, both in animal and human models.

\section{Conclusions}

PNX-14 supplementation significantly prevents the formation of duodenal ulcers induced by IND. In addition, the preventive effects of PNX-14 were superior to FA in several markers such as inflammatory cytokines and catalase activity. These observations suggest a promising anti-inflammatory role for PNX-14 in the gastrointestinal system with potential therapeutic implications in gastrointestinal inflammatory disorders such as IBD.

Acknowledgements This work was kindly supported by the Science and Research Branch, Islamic Azad University, Tehran, Iran."

Author Contributions All authors [contributed to the study's conception and design. YZR and NP performed material preparation and data analysis. YYZR pwrote the first draft of the manuscript. SH and SHSB performed the writing review, editing, land data analysis."

Funding This research received no funding."

?.

\section{Declarations}

Conflict of interest The authors declare that they have no conflict of interest.

\section{References}

Abdullah N, Defaye M, Altier C (2020) Neural control of gut homeostasis. Am J Physiol Gastrointest Liver Physiol 319:718-732. https://doi.org/10.1152/ajpgi.00293.2020 
Bertrand RL, Eze MO (2014) Modifying polyacrylamide background color for the nitroblue tetrazolium-based superoxide dismutase staining assay. Adv Enzyme Res 2:77-81. https://doi.org/10.4236/ aer.2014.22008

Billert M, Rak A, Nowak KW, Skrzypski M (2020) Phoenixin: more than reproductive peptide. Int J Mol Sci 21:8378. https://doi.org/ 10.3390/ijms21218378

Bonaz B, Bazin T, Pellissier S (2018) The vagus nerve at the interface of the microbiota-gut-brain axis. Front Neurosci 12:49. https:// doi.org/10.3389/fnins.2018.00049

Buhmann H, le Roux CW, Bueter M (2014) The gut-brain axis in obesity. Best Pract Res Clin Gastroenterol 28:559-571. https://doi. org/10.1016/j.bpg.2014.07.003

Carabotti M, Scirocco A, Maselli MA, Severi C (2015) The gut-brain axis: interactions between enteric microbiota, central and enteric nervous systems. Ann Gastroenterol 28:203-209

Chen W-C, Liu Y-B, Liu W-F, Zhou Y-Y, He H-F, Lin S (2020) Neuropeptide $\mathrm{Y}$ is an immunomodulatory factor: direct and indirect. Front Immunol 11:2624. https://doi.org/10.3389/fimmu.2020. 580378

De Leon JAD, Borges CR (2020) Evaluation of oxidative stress in biological samples using the thiobarbituric acid reactive substances assay. J Vis Exp. https://doi.org/10.3791/61122:e61122

De Vadder F, Mithieux G (2015) Glucose homeostasis and gut-brain connection. Med Sci (Paris) 31:168-173. https://doi.org/10.1051/ medsci/20153102013

Dinan TG, Cryan JF (2017) Gut-brain axis in 2016: brain-gut-microbiota axis - mood, metabolism, and behaviour. Nat Rev Gastroenterol Hepatol 14:69-70. https://doi.org/10.1038/nrgastro.2016.200

Emge JR, Huynh K, Miller EN, Kaur M, Reardon C, Barrett KE, Gareau MG (2016) Modulation of the microbiota-gut-brain axis by probiotics in a murine model of inflammatory bowel disease. Am J Physiol Gastrointest Liver Physiol 310:989-998. https://doi.org/ 10.1152/ajpgi.00086.2016

Fakhoury M, Negrulj R, Mooranian A, Al-Salami H (2014) Inflammatory bowel disease: clinical aspects and treatments. J Inflamm Res 7:113-120. https://doi.org/10.2147/JIR.S65979

Graff LA, Walker JR, Clara I, Lix L, Miller N, Rogala L, Rawsthorne $P$ et al (2009) Stress coping, distress, and health perceptions in inflammatory bowel disease and community controls. Am J Gastroenterol 104:2959-2969. https://doi.org/10.1038/ajg.2009.529

Haber MM, Lopez I (1999) Gastric histologic findings in patients with nonsteroidal anti-inflammatory drug-associated gastric ulcer. Mod Pathol 12(6):592-598

Hansen JJ, Sartor RB (2015) Therapeutic manipulation of the microbiome in IBD: current results and future approaches. Curr Treat Options Gastroenterol 13:105-120. https://doi.org/10.1007/ s11938-014-0042-7

Hazel K, O'Connor A (2020) Emerging treatments for inflammatory bowel disease. Ther Adv Chronic 11:1-11. https://doi.org/10. $1177 / 2040622319899297$

Holzer P, Farzi A (2014) Neuropeptides and the microbiota-gut-brain axis. Adv Exp Med Biol 817:195-219. https://doi.org/10.1007/ 978-1-4939-0897-4_9

Houser MC, Tansey MG (2017) The gut-brain axis: is intestinal inflammation a silent driver of Parkinson's disease pathogenesis? NPJ Parkinsons Dis 3:1-9. https://doi.org/10.1038/s41531-016-0002-0

Krawisz J, Sharon P, Stenson W (1984) Quantitative assay for acute intestinal inflammation based on myeloperoxidase activity: assessment of inflammation in rat and hamster models. Gastroenterology 87:1344-1350. https://doi.org/10.1016/0016-5085(84)90202-6
Luna RA, Foster JA (2015) Gut brain axis: diet microbiota interactions and implications for modulation of anxiety and depression. Curr Opin Biotechnol 32:35-41. https://doi.org/10.1016/j.copbio. 2014.10.007

Maaser C, Langholz E, Gordon H, Burisch J, Ellul P, Ramirez VH, Karakan T et al (2017) European Crohn's and Colitis Organisation: topical review on environmental factors in IBD. J Crohns Colitis 11:905-920. https://doi.org/10.1093/ecco-jcc/jjw223

Mayer EA, Padua D, Tillisch K (2014) Altered brain-gut axis in autism: comorbidity or causative mechanisms? Bioessays 36:933-939. https://doi.org/10.1002/bies.201400075

Nimer NA, Ismael NS, Abdo RW, Alkhammas SYT, Aga QAA (2020) Pharmacology of neuropeptides: substance P, vasoactive intestinal peptides, neuropeptide Y, calcitonin peptides and their receptors. Frontiers in pharmacology of neurotransmitters. Springer, Singapore, pp 503-551

Ozturk CC, Oktay S, Yuksel M, Akakin D, Yarat A, Kasimay Cakir O (2015) Anti-inflammatory effects of nesfatin-1 in rats with acetic acid-induced colitis and underlying mechanisms. J Physiol Pharmacol 66:741-750

Pałasz A, Rojczyk E, Bogus K, Worthington JJ, Wiaderkiewicz R (2015) The novel neuropeptide phoenixin is highly co-expressed with nesfatin-1 in the rat hypothalamus, an immunohistochemical study. Neurosci Lett 592:17-21. https://doi.org/10.1016/j.neulet. 2015.02.060

Sanz JA, El Aidy S (2019) Microbiota and gut neuropeptides: a dual action of antimicrobial activity and neuroimmune response. Psychopharmacol 236:1597-1609. https://doi.org/10.1007/ s00213-019-05224-0

Schalla MA, Stengel A (2018) Phoenixin-a pleiotropic gut-brain peptide. Int J Mol Sci 19:1726. https://doi.org/10.3390/ijms19061726

Shangari N, O'Brien PJ (2006) Catalase activity assays. Curr Protoc Toxicol 27:7.7.1-7.7.16. https://doi.org/10.1002/0471140856. tx0707s27

Sinagra E, Utzeri E, Morreale GC, Fabbri C, Pace F, Anderloni A (2020) Microbiota-gut-brain axis and its affect inflammatory bowel disease: pathophysiological concepts and insights for clinicians. World J Clin Cases 8:1013-1025. https://doi.org/10.12998/ wjcc.v8.i6.1013

Walker JR, Ediger JP, Graff LA, Greenfeld JM, Clara I, Lix L, Rawsthorne $P$ et al (2008) The manitoba IBD cohort study: a population-based study of the prevalence of lifetime and 12-month anxiety and mood disorders. Am J Gastroenterol Suppl 103:1989-1997

Wang J, Zheng B, Yang S, Tang X, Wang J, Wei D (2020) The protective effects of phoenixin-14 against lipopolysaccharide-induced inflammation and inflammasome activation in astrocytes. Inflamm Res 69:779-787. https://doi.org/10.1007-2Fs00011-020-01355-9

Wei P, Keller C, Li L (2020) Neuropeptides in gut-brain axis and their influence on host immunity and stress. Comput Struct Biotechnol J 18:843-851. https://doi.org/10.1016/j.csbj.2020.02.018

Yuan T, Sun Z, Zhao W, Wang T, Zhang J, Niu D (2017) Phoenixin: a newly discovered peptide with multi-functions. Protein Pept Lett 24:472-475. https://doi.org/10.1111/j.15720241.2008.01980.x

Publisher's Note Springer Nature remains neutral with regard to jurisdictional claims in published maps and institutional affiliations. 